\title{
A produção agrícola de base familiar na Serra Macaense e sua relação com a conservação das águas e os modelos de desenvolvimento de Macaé-RJ
}

\author{
Alice Sá Rego Azevedo ${ }^{1}$ \\ Universidade Federal do Rio de Janeiro - UFRJ \\ Rodrigo Lemes Martins ${ }^{2}$ \\ Universidade Federal do Rio de Janeiro - UFRJ
}

\section{RESUMO}

O alto e médio curso do Rio Macaé tem estado em foco devido às demandas de crescimento do município e à necessidade de garantir a segurança hídrica. Diante desse quadro, o presente trabalho intenta identificar modelos de produção agrícola desenvolvidos na sub-bacia hidrográfica do Alto Rio Macaé, que favorecem a conservação ambiental, aliada às principais atividades econômicas da região: agricultura e turismo. Também foram revistas fontes documentais que denotam a participação dos agricultores e como os mesmos figuram em planos de gestão territorial, considerando sua importância para a conservação das águas. Foram realizadas entrevistas com agricultores locais, levantamento de projetos de gestão territorial e revisão bibliográfica. Os resultados constatam que os agricultores desenvolvem práticas que contribuem para a conservação da região e se mostram organizados e participativos nas formulações de políticas que permitem e permitiram a acomodação de uma estrutura de turismo local, inclusive fomentando redes de agroturismo. Os documentos de gestão avaliados evidenciam a participação dos agricultores, apresentando propostas de integração da cultura local com novas técnicas agrícolas e atividades turísticas como caminhos para a sustentabilidade. Essas iniciativas são cruciais para o desenvolvimento sustentável do município, considerando a importância do fortalecimento de ações que garantam a sobrevivência de outros modos de produção, no momento atual, que se mostra crítico para a diversificação da sua matriz econômica baseada no petróleo e gás.

Palavras-chave: Conservação Ambiental. Bacia Hidrográfica. Agricultura. Turismo. Sustentabilidade.

\begin{abstract}
The middle and upper reaches of the Macaé River basin have been focused due the growth demands of the municipality and this importance to guarantee water security. In view of the present work, identify models of agricultural production developed in one sub-basin of the upper Macaé River, which favor environmental conservation, combined with the main economic activities of the region, agriculture and tourism. We also accesses documents that denote the participation of farmers and how they figure in territorial management plans, considering their importance for water conservation. Interviews were carried out with local farmers and bibliographic review consider territorial projects. The results show that farmers develop practices that contributed to regional conservation and are organized and participatory in policy formulations that allow the accommodation of local tourism structure, including promoting agritourism networks. Regional management plans attest the participation of farmers in the local policy planning, integrating local culture with new agricultural techniques and tourist activities as paths to sustainability. These initiatives are crucial for the sustainable development of the municipality, considering the importance of strengthening actions that guarantee other modes of production, now, which shows critical for the diversification of its petroleum dependence.
\end{abstract}

Keywords: Environmental Conservation. Hydrographic Basin. Agriculture. Tourism. Sustainability.

${ }^{1}$ Mestranda no Programa de Pós Graduação em Ciências Ambientais e Conservação, da UFRJ.

2 Professor adjunto da Universidade Federal do Rio de Janeiro atuando junto ao Núcleo de Pesquisas em Ecologia e Desenvolvimento Socioambiental de macaé (NUPEM) e ao Programa de Pós-Graduação em Ciências Ambientais e Conservação. 


\section{Introdução}

A água é um recurso essencial à vida e vem adquirindo, nas últimas décadas, importância socioeconômica, política e cultural cada vez maior devido à sua irregular distribuição espacial no planeta. A sua escassez, em algumas partes do globo, já é considerada uma ameaça global, conforme destacado na $10^{\mathrm{a}}$ edição do Fórum Econômico Mundial ocorrido em Genebra, em 2015 (Brauman, Richter, Postel, Malsy, M \& Florke, 2016).

Conforme apontado pela Organização das Nações Unidas para Alimentação e Agricultura (FAO), a promoção da sustentabilidade das montanhas pode cumprir a importante função de beneficiar as terras baixas, pela garantia do abastecimento adequado de água e alimentos, pela estabilidade ambiental, pela conservação da biodiversidade, da cultura, de lazer, entre outros elementos (Wymann von Dach, Romeo, Vita, Wurzinger \& Kohler, 2013). O reconhecimento da FAO sobre a relevância das regiões montanhosas reflete uma tensão crescente sobre o acesso a importantes recursos para a sobrevivência humana e, consequentemente, sobre essas áreas, em decorrência do crescimento populacional e industrial, em especial nas regiões litorâneas, onde o escoamento portuário é facilitado.

O município de Macaé (RJ) engloba mais de 80\% da bacia hidrográfica do Rio Macaé em seu território (Instituto Estadual do Ambiente [INEA], Comitê de Bacia Hidrográfica dos Rios Macaé e das Ostras [CBH Macaé] \& Consórcio Macaé/Ostras, 2014; Martins, Molisani \& Rocha, 2019); apresenta-se como excelente retrato das dinâmicas e conflitos que se estabelecem no âmbito de formulação de políticas municipais e suas tensões com relação aos municípios vizinhos, incluídos na bacia do Rio Macaé. Por abranger seis municípios, com diferentes realidades sociais, políticas, ambientais e econômicas, a gestão dessa bacia torna-se complexa (Rego, 2010).

A cidade de Macaé tem um histórico interessante associado ao desenvolvimento de um conjunto de empresas necessárias ao provimento de suprimentos para a cadeia produtiva de petróleo. O desenvolvimento da exploração do petróleo na região teve início a partir do final da década de 1970, quando Macaé passou por um intenso processo de urbanização, crescimento demográfico e expansão da área urbana de forma desordenada (Esteves et al., 2015). A partir de 2016, após mais um período de crise do mercado mundial e interno, o processo de crescimento sofreu uma redução, que forçou a adoção de medidas de reestruturação econômica do município, por meio da encampação de projetos de infraestrutura para aproveitamento do gás natural de petróleo. A chegada desses novos empreendimentos, consequentemente, trouxe de volta à pauta dos meios de comunicação e espaços de discussão o conflito existente entre modelos de desenvolvimento do território, considerando o acesso à água (Ferreira, Quintanilha, Guimarães, \& Molisani, 2019).

As discussões sobre sustentabilidade também emergiram, uma vez que se torna premente, para o novo momento de crescimento econômico do município, que sejam pensadas formas de coordenar os diferentes projetos em disputa. É preciso garantir a boa qualidade ambiental, principalmente nas questões relativas aos recursos hídricos, que envolvem diretamente o uso e ocupação do solo. A manutenção da qualidade e da quantidade de água do Rio Macaé é fundamental para o abastecimento humano e para os seus diversos usos (Ferreira et al., 2019; Silva, Becker \& Martins, 2015).

Nesse contexto, uma série de questionamentos começa a emergir sobre o estado de conservação das águas do município e a segurança hídrica da população e, de maneira implícita, a capacidade de abastecimento dos novos modelos de desenvolvimento do território. Cabe destacar que o atual estado de conservação da paisagem montanhosa da região do Alto Rio Macaé conta com cerca de 75\% com cobertura florestal (Floresta Ombrófila Densa), em um mosaico de estágios sucessionais e fitofisionomias, incluindo as áreas de Campo de Altitude; e cerca de $23 \%$ de áreas alteradas sob influência da ocupação humana (INEA et al., 2014). A ocupação se dá principalmente com pequenas propriedades rurais dedicadas à agricultura familiar, sítios de lazer e pecuária, além de pequenos núcleos urbanos que recebem visitação turística, como os distritos de Lumiar e São Pedro da Serra, em Nova Friburgo, e o Sana, distrito de Macaé. Esses distritos estão inseridos em Áreas de Proteção Ambiental (APA): APA Estadual Macaé de Cima e APA do Sana, respectivamente (Figura 1.1). 


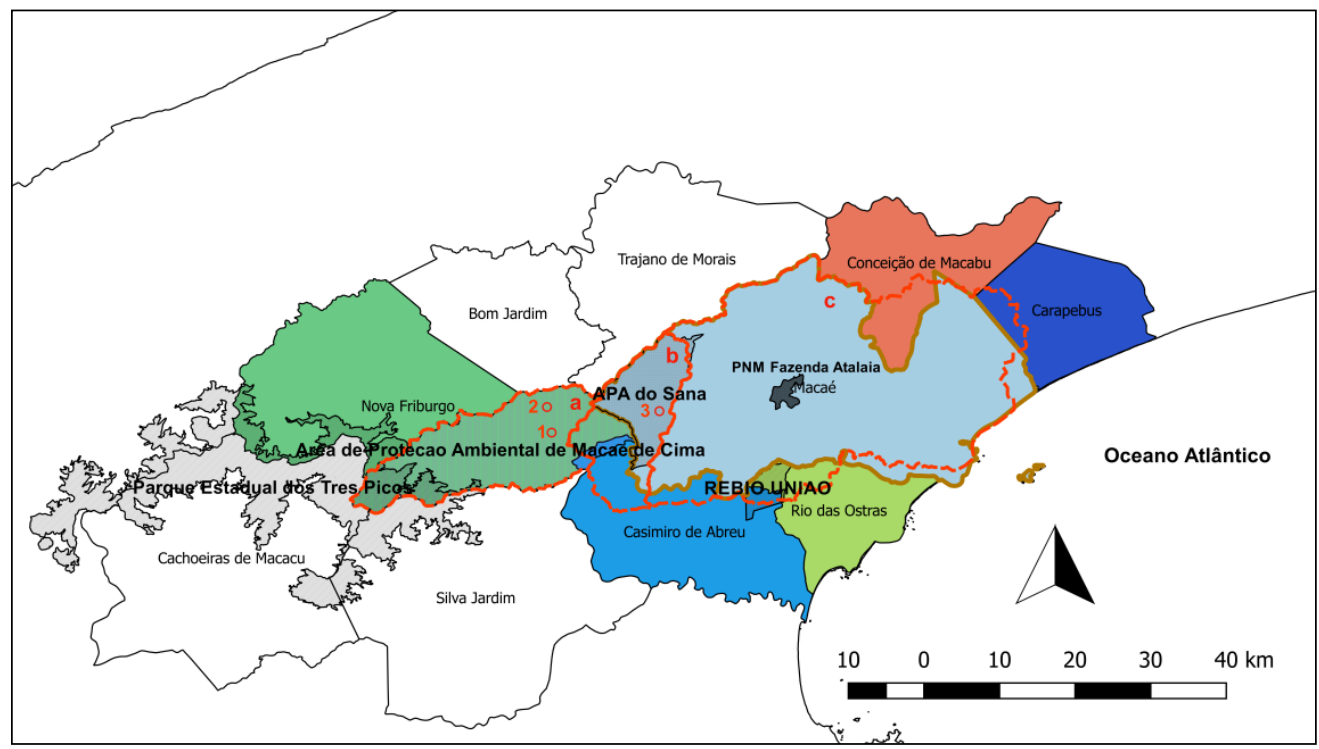

Figura 1.1 Bacia Hidrográfica do Rio Macaé delimitando o Alto (a), Médio (b) e Baixo Curso (c).

Nota: Os municípios em cores possuem parte do território pertencente à Bacia Hidrográfica. Porções hachuradas representam Unidades de Conservação Federais, Estaduais e Municipais. E pontos representam distrito de Lumiar (1), São Pedro da Serra (2) e Sana (3). APA: Área de Proteção Ambiental; PNM: Parque Natural Municipal; REBIO: Reserva Biológica.

Os usos de água mais significativos em termos de volume nessa região estão relacionados com a aquicultura (feita com introdução de espécies exóticas) e a irrigação em pequenas propriedades agrícolas familiares. No entanto, os usos vinculados ao abastecimento público e ao lazer são os mais preocupantes, principalmente em relação à qualidade $(\mathrm{CBH}$ Macaé, 2016; Ferreira \& Rego, 2017; INEA et al., 2014). Sobre os agricultores pairam as críticas em relação ao grau de substituição de áreas florestais por culturas e pastagens; às criações de animais, que, quando confinados, geralmente destinam seus efluentes para os rios (CBH Macaé, 2016) e a utilização de agrotóxicos na agricultura, o que influencia diretamente na qualidade dos corpos hídricos (INEA, 2014; Santilli, 2009; Viva Rio, 2004).

Com base no exposto, o presente trabalho visa a identificar modelos de produção desenvolvidos por agricultores da Região Serrana, com potencial de conservação da biodiversidade, dos solos e das águas. Objetiva também levantar estudos e projetos relativos à importância da conservação ambiental aliada às práticas agrícolas e ao turismo sustentável na sub-bacia hidrográfica do Alto Rio Macaé. Pretende, assim, possibilitar a acomodação de todos os distintos modelos de desenvolvimento do território, de forma a garantir a efetivação da sustentabilidade como um caminho para manter e melhorar a qualidade ambiental e, consequentemente, a qualidade de vida dessas populações (Azevedo, 2017; Carneiro \& Palm, 2015; INEA, 2014; INEA et al., 2014; Viva Rio, 2004).

\section{Metodologia}

Foram realizadas entrevistas com agricultores(as), pesquisas documental e bibliográfica. A pesquisa documental se caracteriza por um estudo orientado por documentos disponíveis, que ainda não receberam um tratamento analítico ou que podem ser reexaminados a fim de uma nova interpretação ou complementação (Demo, 2002; Gil, 1987). A pesquisa bibliográfica foi referente a documentos de projetos, planejamentos e iniciativas locais e regionais, sobre os temas turismo, agricultura e águas no Alto Rio Macaé, 
especialmente aqueles que buscavam integrá-los e relacioná-los às suas influências na bacia hidrográfica do Rio Macaé como um todo. Foram destacadas as principais características de cada documento, assim como seus direcionamentos para a construção de um desenvolvimento em bases sustentáveis, a partir da agricultura e do turismo.

As entrevistas foram semi-estruturadas e sua elaboração foi baseada na metodologia "geradora de dados" (Posey, 1986), na qual se utilizam tópicos de informações e explicações e perguntas do tipo "fale-me sobre isso". Considera-se que "questões abertas conferem uma certa liberdade de resposta ao entrevistado, mas sempre dentro dos limites impostos pelo problema" (Poupart, 2012, p. 225). Na elaboração das entrevistas houve o cuidado de evitar o uso de conceitos etnocêntricos, já carregados de significados e preconceitos (Posey, 1986).

Os critérios para selecionar os(as) agricultores(as) foram: pertencer a uma família tradicional; ter relação histórica com a atividade agrícola, mesmo que a agricultura não seja a atividade principal, e, atualmente, sejam pluriativos. Porém, agricultores já aposentados também foram incluídos por representarem uma rica fonte de informação e conhecimentos, mesmo que afastados da atividade agrícola. Foram entrevistados seis agricultores que residem na APA Estadual Macaé de Cima no mês de setembro/2019. Os agricultores são identificados no texto pela letra "A" seguidas de números cardinais (Ex. A1, A2, A3...). A opção pela não identificação das fontes utilizadas nas entrevistas segue orientação do Comitê Nacional de Ética em Pesquisa, onde a presente pesquisa está registrada sob o CAAE: 12949319.8.0000.5699.

As entrevistas tiveram o objetivo de obter uma visão geral do tema pesquisado e identificar a visão dos(as) agricultores(as) sobre (Silva, Gobbi \& Simão, 2005): como fazem agricultura; como as gerações anteriores faziam agricultura; as transformações das suas práticas de cultivo ao longo do tempo; as transformações da região (paisagem, clima, cultura, economia); a relação das suas práticas agrícolas com os ecossistemas locais e a conservação ambiental; entre outras questões. As entrevistas foram marcadas por ligações telefônicas e realizadas nas unidades produtivas e/ou nas residências dos entrevistados.

\section{Resultados}

\section{Entrevistas}

Dos seis agricultores entrevistados, dois já estão aposentados com idade avançada, mais de 90 anos (A5 e A6); três trabalham com agricultura, mas a principal fonte de renda vem de outras atividades - A1 e A4 trabalham na construção civil e A2 trabalha com artesanato de tear manual (44 anos, 52 anos e 45 anos, respectivamente); e apenas um vive exclusivamente da agricultura (A3, 76 anos). Todos têm relação com a agricultura desde que nasceram, com pais e avós agricultores. Os três agricultores pluriativos afirmaram que mantêm a agricultura por acreditar na agricultura familiar, pela paixão por plantar, por manter e reproduzir a cultura local e para produzir alimento saudável para consumo próprio. Os quatro agricultores ativos têm em suas propriedades áreas de horta, pomar e lavoura, como eles mesmo diferenciam seus sistemas de produção.

De maneira geral, todos comercializam seus produtos, porém um dos principais objetivos dos plantios dos entrevistados é o consumo próprio ou, como os mais idosos falam, é "pro gasto" - termo utilizado localmente, que significa para consumo próprio, subsistência. Apenas A3 possui 3 hectares de produção de banana destinada para venda. A3 também é o único que utiliza adubação química com NPK; enquanto os outros utilizam esterco animal e/ou técnicas de adubação verde. A necessidade de adubação depende do tipo de cultivo. Os(as) entrevistados(as) relataram diversas maneiras para combater as pragas e doenças. No entanto, nas últimas décadas, percebe-se a intensificação do uso de agroquímicos que geram impactos negativos no solo, na fauna, na água e no ser humano.

Evidenciou-se uma interessante percepção de A2 em relação ao seu plantio e à interação com pragas. $\mathrm{O}$ (a) entrevistado(a) entende que, ao manter um plantio diverso em espécies, já estaria fazendo um controle biológico e não precisaria usar produtos para combater pragas ou doenças, caso apareçam. 
Às vezes, assim, aparece uma formiga, mas aí, se eu coloco uma coisa mais cheirosa, um manjericão, uma coisa assim, alecrim de horta, elas já mudam de ideia. E tem tanto mato assim, tudo tão misturado, que elas se distraem em outra coisa (A2, comunicação pessoal, 22/09/2019).

Algumas práticas, principalmente as de A1, A2 e A4, têm características ecológicas reconhecidamente desejáveis para agroecossistemas sustentáveis, tais como: a intensificação da ciclagem de nutrientes pela adubação verde; o aumento da diversidade de espécies; o controle biológico para melhorar a biodiversidade funcional; a utilização de variedades locais (sementes crioulas de milho e feijão; variedades de inhame e mandioca); o cultivo de espécies nativas; o uso de insumos localmente disponíveis; e a proteção e a recuperação das nascentes de suas propriedades (Altieri, 2012; Empresa Brasileira de Pesquisa Agropecuária [EMBRAPA], 2006).

Dentre as espécies nativas cultivadas, vale evidenciar o relato de dois agricultores sobre plantar a Palmeira Jussara (Euterpe edulis Mart.), por ser uma das principais fontes de palmito na Mata Atlântica. Eles relataram que plantaram essa espécie para os seus frutos atraírem animais e como uma forma de valorizar essa planta de maneira diferente, que não seja pelo palmito. Também foi citada a preferência por plantar espécies frutíferas nativas para atrair animais silvestres e, assim, os(as) agricultores(as) poderem ficar admirando-os. Além de ser uma fonte de alimento para a fauna local, que cada vez mais está perdendo seus habitats, fato reforçado na fala de A2, "eles tão ficando encurralado e sem opção né. Ai tem que comer o que tem" (A2, comunicação pessoal, 22/09/2019). Esses elementos evidenciam uma interação entre as propriedades, suas práticas e os animais silvestres.

A prática tradicional mais mencionada foi a prática do pousio, o "descanso da terra"; feita principalmente pelos pais e avós dos entrevistados, e que pode ser assumida como base de todo o agroecossistema. Foi relatado que, quando uma área de "macega" ou "capoeira" 3 já estava com árvores com troncos com cerca de $10 \mathrm{~cm}$ de diâmetro, que já serviam para lenha, essa área estava boa para cortar e plantar. Então, a família e/ou os vizinhos se reuniam para cortar as árvores, limpar o terreno, esperar secar para fazer o aceiro e queimar. Foi reforçado por todos os participantes da pesquisa que havia muito cuidado no momento da queimada, para evitar que o fogo migrasse para outras áreas, principalmente para as florestas. A2 lembra que o pessoal cuidava, porque sabia que precisava da floresta para poder produzir alimento, "se a floresta não nascesse não ia ter terreno para plantar" (A2, comunicação pessoal, 22/09/2019). Normalmente, durante os meses de agosto e setembro, meses secos, era o período de queimada, a "queima das roças".

Uma característica interessante do preparo do terreno era que, após a queimada, os agricultores não retiravam os "tocos" das árvores cortadas e não reviravam o solo e nem as raízes; abriam a cova apenas nos locais onde iam semear. Esses "tocos" de árvores começavam a rebrotar e, mais ou menos depois de dois anos de uso de determinada área, eles selecionavam os melhores brotos para crescer. Então, deixavam os brotos se desenvolverem até virar "macega" e "capoeira" novamente. Em média, usavam uma área durante 2, 3 anos, no máximo 4, e obtinham pelo menos três grandes colheitas. O tempo de descanso era de 3 a 5 anos, podendo ficar até 8, 9 anos; dependia do espaço disponível e da necessidade ou não de voltar para a mesma área, conforme também observado por Villas Boas (2017). As culturas plantadas nas áreas queimadas eram feijão, mandioca, batata inglesa, inhame e milho, como culturas principais, além de outros legumes e hortaliças. Às vezes, plantavam árvores de crescimento rápido para lenha.

Segundo os entrevistados, essas práticas se tornaram mais raras, devido ao processo de modernização agrícola, ao crescimento das vilas de São Pedro da Serra e Lumiar e à aplicação da Legislação Ambiental de maneira truculenta. $\mathrm{O}$ abandono dessas práticas acima relatadas representa a perda de parte da cultura local (Carneiro, 2010; INEA, 2014; Rego, 2010). Cabe destacar que o pousio é considerado uma forma de tratamento, que visa melhorar as condições nutricionais do solo e permite a formação de capoeiras, úteis ao trânsito de algumas espécies

\footnotetext{
3 "Macega": etapa dos primeiros anos da sucessão florestal, quando crescem as plantas pioneiras, como as citadas: capim gordura, assa peixe, capixingui, fumeiro. A partir de uns seis anos a floresta se torna "capoeira", e com 8,9 anos vira o "capoeirão"; "para quem não conhece parece uma "mata nativa"”" (A1, comunicação pessoal, 12/09/2019).
} 
animais e, por isso, é responsável também pela manutenção da diversidade de espécies nativas. É um tipo de agricultura, portanto, mais alinhado à conservação (Altieri, 2012; Toledo \& Barrera-Bassols, 2015).

Em relação ao início da aplicação da legislação ambiental, todos os entrevistados citaram a maneira agressiva da fiscalização dos órgãos ambientais. Principalmente, a partir da criação da APA Estadual Macaé de Cima, em 2001, que gerou diversos conflitos. Conforme observado na fala de A1, no início do processo, a atuação dos órgãos ambientais foi truculenta e provocou revolta. Para o entrevistado, o trabalho no campo exige muita dedicação, o que torna difícil acompanhar a legislação e as demandas burocráticas impostas, muitas delas limitadoras do uso de práticas e da liberdade na propriedade. A1 também relatou que, por meio do diálogo e da organização, hoje, há uma relação mais amigável e maior espaço para negociações junto aos órgãos ambientais.

As mudanças culturais, sociais e ambientais na região aparecem nas falas dos entrevistados, por meio de relatos referentes à presença de mais áreas florestadas e menos áreas de cultivo do que há 30/50 anos atrás. De acordo com os entrevistados, ainda se aproveita o máximo possível da área das propriedades, mas, com a adequação às legislações ambientais. Entretanto, a explicação para tal mudança se justifica na maior oferta de empregos na região e o acesso facilitado aos centros urbanos, que levam agricultores e seus filhos a mudarem de atividade. Relatou-se que parte das famílias de agricultores adotou um sistema de pluriatividade, como forma de se manter na agricultura e diversificar a fonte de renda; muitas dessas outras atividades exercidas são relacionadas ao turismo local (Carneiro, 2010). A diminuição da agricultura foi também relacionada com o aumento de unidades habitacionais, no modelo de segunda residência de caráter rural e do turismo local. Esse processo causou o crescimento contínuo da especulação imobiliária e da ocupação desordenada. Nesse contexto, surge na fala de três dos entrevistados a busca por um alinhamento com as demandas do turismo praticado na localidade, especialmente, pela prática do agroturismo, para aumentar a geração de renda complementar e garantir a manutenção da atividade agrícola. A iniciativa identificada, que inclui os entrevistados A1, A2 e A4, visa a estimular circuitos curtos de comercialização de produtos produzidos localmente, por meio da criação de uma rede de agroturismo regional, em que cada um de seus integrantes oferece serviços e produtos específicos.

Sobre o abandono da agricultura pelos jovens, A2 contou que os filhos dos agricultores com cerca de 40 anos não estão na agricultura. Corroborou, assim, a fala de A1sobre ter pouquíssimos jovens com 20 anos trabalhando na lavoura. Para A1, se os jovens não se organizarem, a agricultura vai deixar de existir na região. Isso não é positivo, pois se permitir o aumento da especulação imobiliária, vai impactar muito mais a natureza local. "Os cursos nossos d'água vão ser mexidos, nossas nascentes vão ser poluídas por esgoto" (A1, comunicação pessoal, 12/09/2019). Ao falar isso, A1 citou um poço no Rio São Pedro, um pouco após o centro do distrito, onde, antigamente, era possível tomar banho e, hoje em dia, está poluído com esgoto; “(...) cresceu esse número de casa (sic.) e cresceu a poluição” (A1, comunicação pessoal, 12/09/2019). Ele afirmou que o agricultor leva a culpa de vários impactos e que essa parte da poluição das águas por esgoto pelas novas casas e pousadas é pouquíssimo fiscalizada. A1 também alertou que, se não der atenção à especulação imobiliária, daqui a uns anos "não tem mais água". Atualmente São Pedro da Serra e Lumiar já enfrentam problemas de abastecimento de água em determinadas épocas, mesmo naquelas casas que são abastecidas por nascentes próprias.

A1 citou várias vezes que a agricultura familiar é o futuro da humanidade. "É o passado e o futuro. Porque você, formando um bom agricultor familiar, você tá formando um excelente ambientalista" (A1, comunicação pessoal, 12/09/2019). Para ele, se tivesse um investimento para formação de agricultores, os agricultores saberiam dos benefícios que eles mesmos têm quando preservam a nascentes, as matas do entorno e as matas ciliares. Essa formação pode ser feita pela educação rural formal ou pela possibilidade dos jovens trabalharem na lavoura. A1 comentou que as grandes nascentes do mundo estão nas mãos de cinco ou seis empresas. $\mathrm{E}$, para ele, a agricultura familiar pode romper com esse sistema: "Pela simplicidade e pela força que nós temos" (A1, comunicação pessoal, 12/09/2019).

Um dos tópicos da entrevista era sobre o que os(as) agricultores(as) consideram como uma natureza saudável e quais práticas eles(as) podem fazer para contribuir com essa 
natureza. Percebeu-se que, no geral, um elemento importante para uma natureza ser considerada saudável é ter um ar puro e limpo. Para A2, um ambiente saudável é aquele lugar onde tem plantas, animais e pessoas, em que todo mundo consegue habitar junto, especialmente na área rural. Ela considera que

\begin{abstract}
A beira do rio a gente tem que manter com mais árvores possível. Que assim... não é um bem só nosso, né. É geral. E, se a água dele sumir, vai fazer falta pra todo mundo. Então, tem que manter ele limpo, né. Porque eu acho que o rio é uma riqueza que a gente tem. Mas, aqui todo mundo cuida, todo mundo sabe. As nascentes né, também que é outro tesouro, que a gente tem. Tem que cuidar! (A2, comunicação pessoal, 22/09/2019, grifo nosso).
\end{abstract}

Para A3, uma natureza saudável é aquele lugar onde se tem ar puro para respirar, água à vontade, sem precisar se preocupar com falta d’água, e muitos animais, "como tinha antigamente, bicho do mato memo... passarinho, beija-flor, né, tudo é bonito né. $\mathrm{E}$ tá bem diferente hoje" (A3, comunicação pessoal, 13/09/2019). Para A3, é preciso haver a preservação ambiental, mas também é preciso aumentar a produção de alimentos. Para ele isso é complicado, é um conflito; mas é necessário conciliar a produção e a preservação. "Produzir alimento e preservar a natureza aí, as florestas, né” (A3, comunicação pessoal, 13/09/2019).

\title{
Documentos de planejamento e gestão
}

Em relação aos documentos e iniciativas levantados, primeiramente, identificaram-se os principais documentos de planejamento e gestão ambiental da região: o Plano de Recursos Hídricos da Região Hidrográfica VIII do estado do Rio de Janeiro (PRH RH VIII); o Plano de Manejo da APA Estadual Macaé de Cima; o Plano de Manejo da APA do Sana - Fase 1 e o Diagnóstico do Programa Produtor de Água, finalizado em 2016.

O PRH da RH VIII é um documento composto por doze relatórios e apresenta estratégias para alcançar os objetivos de: compatibilizar as demandas e as disponibilidades hídricas em termos quantitativos e qualitativos; reduzir os impactos de cheias e fomentar as atividades estruturantes do uso sustentável da água e do ambiente. A principal bacia hidrográfica da Região Hidrográfica VIII é o Rio Macaé. Há a preocupação para delimitação de estratégias distintas para a parte baixa, média e alta da $\mathrm{RH}$, reconhece-se que essas áreas não têm as mesmas demandas e potencialidades (INEA et al., 2014). As principais vocações econômicas apontadas pelo PRH e demais Planos para o Alto Rio Macaé são o turismo de natureza e aventura e a agricultura familiar, que associam uma dinâmica econômica baseada em serviços com a proteção ambiental (INEA, 2014; INEA et al., 2014; Viva Rio, 2004).

$\mathrm{Na}$ análise da região feita para a elaboração do $\mathrm{PRH}$, em 2012, foi constatado que a disponibilidade hídrica de alguns corpos d'água no entorno dos distritos de Lumiar e São Pedro da Serra, usados para o abastecimento humano, já estavam com problemas em relação à sua quantidade. Um exemplo é o Córrego da Sibéria (uma das fontes de abastecimento de São Pedro) que, na época, já estava com $60 \%$ a $80 \%$ de suas águas comprometidas (INEA et al., 2014). Nos últimos anos, observou-se que os distritos de Lumiar e São Pedro já enfrentam interrupção no abastecimento e racionamento de água. Geralmente, esse racionamento é feito no fim do período da seca (setembro/outubro), principalmente em feriados, quando as cidades estão cheias de turistas (Azevedo, 2017).

O PRH é estruturado com doze ações propostas e 24 programas que as detalham e orientam (INEA et al., 2014). Dentre estes, destacam-se os programas para a agricultura familiar sustentável e de resgate de práticas sustentáveis das populações tradicionais residentes na RH VIII (pescadores e agricultores familiares). Populações que não costumam ser incorporadas nos planos de recursos hídricos (Ferreira \& Rego, 2016; Pina \& V. Ferreira,

2010; Rego, 2010). Os Programas de Ação que abordam os temas de interesse desse artigo, são: (1) Fomento à regularização ambiental das propriedades rurais - boas práticas e acompanhamento dos efeitos dos Pagamentos por Serviços Ambientais: Programa Produtor de Água - PSA; (2) Inventário e Proteção Participativa de Nascentes - IPN; (3) Resgate e incentivo aos modos de vida e práticas de manejo das populações tradicionais; (4) Ordenamento do turismo; (5) Agricultura familiar na perspectiva de transição para agricultura familiar sustentável (base agroecológica e orgânica). 
O Programa de Fomento à Regularização Ambiental das Propriedades Rurais por Pagamentos por Serviços Ambientais (PSA), apoiado inicialmente pelo Programa Produtor de Água da Agência Nacional de Águas (ANA), é considerado de alta prioridade. O PSA é uma maneira de estimular os proprietários rurais a proteger as nascentes e corpos d'água presentes em suas propriedades (INEA et al., 2014). O Programa Inventário e Proteção Participativa de Nascentes reforça a importância da participação dos proprietários nas ações de proteção das nascentes, que são abundantes na região. No entanto, as nascentes da região vêm secando, ao longo dos anos (INEA et al., 2014), fato identificado nas falas dos diversos agricultores e proprietários rurais entrevistados.

O Programa de Resgate e Incentivo aos Modos de Vida e Práticas de Manejo das Populações Tradicionais é o que está mais voltado à agricultura, pois trata da identificação e do regaste das práticas tradicionais da região para estimular a sua utilização e a reinserção das mesmas. Reforça a valorização do conhecimento tradicional e o estímulo ao diálogo dos saberes entre o conhecimento técnico-científico e o conhecimento tradicional (INEA et al., 2014). O Programa de Agricultura Familiar na Perspectiva de Transição para Agricultura Familiar Sustentável também se baseia no diálogo de saberes. E tem como estratégia dar voz aos agricultores para definição de projetos, que visem reinserir as práticas agrícolas tradicionais sustentáveis na região (INEA et al., 2014).

O Programa de Ordenamento do Turismo também considera a importância da pluriatividade das famílias agricultoras na vinculação com o turismo. Aborda o turismo de base comunitária como uma estratégia para o desenvolvimento sustentável local; aponta atividades de aproximação da comercialização dos produtos da região para consumo dos turistas e cita a inserção das propriedades agrícolas nos roteiros turísticos locais. É um programa de alta prioridade e o seu horizonte de implementação era 2017 (INEA et al., 2014). Mas, apenas em 2019, foi aprovado pelo CBH Macaé um projeto desse Programa, que ainda não teve início - Ordenamento e o Monitoramento do Uso Recreativo e Turístico dos Atrativos Naturais "Encontro Dos Rios" e "Giannini", localizados no distrito de Lumiar (CBH Macaé, 2019).

O território da APA Estadual Macaé de Cima (APAMC) corresponde a 8\% da área total da bacia do Rio Macaé e inclui suas nascentes. O Plano de Manejo dessa Unidade de Conservação é composto por um resumo executivo e seis módulos (INEA, 2014). Um dos objetivos da APAMC é justamente conservar as nascentes do Rio Macaé e seus afluentes, como forma de garantir a manutenção da qualidade e da quantidade de água desses mananciais; como também conservar os importantes remanescentes da Mata Atlântica existentes em seu território. As ações do Plano de Manejo são divididas em nove Planos Setoriais, com 21 programas, que contêm objetivos e 199 atividades, que direcionam os programas. Dentre eles, destacam-se: (1) Plano Setorial de Agricultura; (2) Plano Setorial de Turismo; (3) Plano Setorial de Valorização da Cultura Tradicional; (4) Plano Setorial de Articulação Interinstitucional.

O Plano Setorial de Agricultura tem programas e atividades focados em diferentes aspectos, desde responsabilidades pertinentes ao INEA, às técnicas de manejo sustentável; educação; extensão rural e assistência técnica (INEA, 2014). Esse Plano pode ser considerado uma conquista dos agricultores locais (Azevedo, 2017; Sousa, Azevedo \& Martins, 2019). Esse Plano Setorial possui um programa com atividades que abordam técnicas de manejo sustentável da natureza. Nele são apresentadas ações práticas para serem utilizadas pelos agricultores da região que, em muitos casos, já são ou já foram praticadas localmente, como, por exemplo, técnicas de adubação verde, plantio de espécies nativas e Sistemas Agroflorestais. Esse programa apresenta ações para articular projetos, que visem o reconhecimento do manejo tradicional e das práticas agrícolas para conservação ambiental. Também cita um ponto considerado fundamental para a conservação da natureza pela agricultura na região: a campanha de substituição de agroquímicos, junto com o incentivo de práticas agroecológicas (INEA, 2014). A falta de assistência técnica é relatada como uma das dificuldades dos agricultores da região, como também a repressão dos órgãos ambientais sobre as suas práticas e a ausência do poder público (Carneiro \& Palm, 2015; INEA, 2014; Rego, 2010; Sousa et al., 2019).

Outra conquista da população local presente no Plano de Manejo é o Plano Setorial de Valorização da Cultura Tradicional, que busca resgatar as práticas tradicionais locais 
relativas à agricultura, tais como as festas, a culinária, as músicas, etc. Reforça o estímulo ao diálogo da cultura local com o conhecimento técnico/científico e a valorização dos saberes da comunidade da APA, como direcionamento da gestão. Essa foi uma demanda da população local, desde o início da implantação da APAMC (Rego, 2010; Sousa et al., 2019).

O Plano Setorial de Articulação Interinstitucional tem dois principais objetivos: aplicar na APAMC o projeto de PSA (Programa Produtor de Água), desenvolvido pelo Comitê da Bacia do Rio Macaé, e melhorar a qualidade ambiental da APAMC, com foco em ações para o tratamento e destinação adequados dos resíduos sólidos e efluentes (INEA, 2014).

Por fim, o Plano de Manejo da APA do Sana também precisa ser aqui relacionado, apesar de ter sido publicado em 2004 e ainda estar na sua primeira fase de construção (Viva Rio, 2004). A APA do Sana é municipal, abrange todo o distrito do Sana, na Bacia do Rio Sana, principal contribuinte do Rio Macaé em termos de volume hídrico (Jeronymo, 2012). Tem como objetivos: conservar a biodiversidade da Mata Atlântica regional; proteger os recursos hídricos; promover o desenvolvimento humano e o equilíbrio ecológico da região, a partir da implantação de projetos voltados para a sustentabilidade econômica e ambiental (Viva Rio, 2004). Esse documento cita que as principais vocações do distrito são o ecoturismo e esportes de natureza (Viva Rio, 2004). Cabe destacar que, na ocasião de sua elaboração, o documento já relatava um grau considerável de degradação ambiental e a necessidade de se recuperarem essas áreas, especialmente as matas ciliares. Além de ressaltar o fato do distrito viver uma fase de crescimento populacional, o que tornaria a questão do esgotamento sanitário um problema (Viva Rio, 2004).

O Plano aponta a agricultura orgânica e agroecológica, Sistemas Agroflorestais, apicultura, meliponicultura e a produção associada ao ecoturismo como caminhos para a sustentabilidade local. Essas ações devem ser desenvolvidas por meio do fortalecimento da identidade cultural, ao mesmo tempo em que constituem uma fonte de renda para a população, a partir da valorização e do reestabelecimento das formas tradicionais de produção e do estímulo à adoção de novas tecnologias (Viva Rio, 2004).

Vale evidenciar, nesse documento, a tentativa de apresentar o ordenamento do turismo na região como alternativa para a sustentabilidade do Sana, por demonstrar claramente a natureza emergente de uma situação conflituosa. $O$ ordenamento proposto recomenda um controle do número de turistas, em especial nos acampamentos e áreas de visitação, como as cachoeiras, principal atrativo local, para evitar e minimizar os danos potenciais às comunidades e aos recursos naturais (Viva Rio, 2004). O Plano coloca como alternativa para o desenvolvimento local sustentável ambiental, social e econômico, a criação de condições e alternativas para o desenvolvimento da produção rural e para a ordenação do turismo, baseados na percepção da sociedade local (Viva Rio, 2004).

Outro documento identificado na pesquisa foi o relatório da primeira etapa de execução do Programa Produtor de Água, o Diagnóstico do Programa Produtor de Água, finalizado em 2016 (CBH Macaé, 2016). Esse Programa é desenvolvido pela ANA e tem como foco o estímulo à política de Pagamento por Serviços Ambientais (PSA)4, voltado à proteção hídrica no Brasil

(INEA et al., 2014). A área para iniciar o programa na RH VIII foi o Alto Rio Macaé, definido como a porção da bacia do Rio Macaé a montante do Rio Sana, com 96,3\% do território no município de Nova Friburgo e 3,7 \% no município de Casimiro de Abreu (CBH Macaé, 2016).

A adoção de boas práticas agropecuárias é o ponto central do Programa Produtor de Água. Nesse sentido, é necessário que os proprietários de terra e empreendedores rurais da região tenham acesso à assistência técnica de qualidade, de forma acessível. As práticas consideradas sustentáveis e indicadas pelo Programa são: plantio direto; plantio em nível; Sistemas Agroflorestais; utilização de adubação verde; rotação de culturas; prática do pousio; sistema silvipastoril; piqueteamento e manejo de pastagens; utilização de moirões vivos; implantação de áreas experimentais e adequação tecnológica de sistemas de irrigação (CBH

\footnotetext{
${ }^{4}$ O PSA consiste na transferência de recursos (monetários ou outros) a quem ajuda a manter ou a produzir os serviços ambientais. No Brasil, a noção de serviços ambientais é inserida na legislação como algo associado aos benefícios gerados por um dado ecossistema e sua respectiva biodiversidade, como base para a manutenção da vida no planeta. Esses serviços podem ser: de provisão de bens ou produtos ambientais; reguladores; culturais; e de suporte à vida no planeta. O PSA tem como princípio básico o caráter voluntário tanto de quem presta o serviço, quanto de quem o adquire. A FAO considera o PSA como principal ferramenta para evitar a pressão da agricultura sobre as áreas de florestas (Bursztyn \& Bursztyn, 2012; Lei n. 9.985, 2000)
} 
Macaé, 2016).

O documento volta a apresentar a questão do desenvolvimento do turismo em bases sustentáveis integrado com as atividades agrícolas para viabilizar a conservação dos recursos hídricos na Bacia do Rio Macaé, principalmente no alto curso. Propõe um tipo de turismo que faça parte de um projeto da comunidade, considere a conservação ambiental e respeite a cultura das comunidades locais (CBH Macaé, 2016). O diagnóstico do Produtor de Água mapeou 25 pontos de banho e trilhas ecoturísticas. Todos se encontram em propriedades particulares, mas estão abertos ao público, com ou sem cobrança para entrada. Existem ainda outros vários pontos de banho de rio, porém a maioria é apenas de uso particular de proprietários, pois não há entradas de acesso público (CBH Macaé, 2016). De forma explícita, foi destacado no diagnóstico o conflito causado pelo turismo de lazer entre os visitantes e a população local. Segundo o relatório, diversos problemas têm levado os proprietários a fechar o acesso e uso público dos corpos d'água, como: o descarte inadequado de resíduos; o som alto nos bares e carros; a poluição dos rios e suas margens; a realização de churrascos nas margens dos rios; entre outros. O fechamento do acesso aos pontos de banho aumenta a sobrecarga sobre as áreas abertas ao público (CBH Macaé, 2016) ou gera áreas de acesso restrito a pessoas de alto poder aquisitivo, o que não significa necessariamente um maior cuidado ambiental.

\section{Discussão}

Por meio das entrevistas foram identificadas características típicas de unidades de produção tradicional e camponesa, com reconhecida influência na conservação das águas, dos solos, da biodiversidade e da cultura local. Podem ser citadas a adoção de estratégias de uso múltiplo dos recursos de maneira a maximizar a variedade de produtos para suprir as necessidades familiares e a formação de um mosaico de ecossistemas na paisagem, incluindo florestas primárias e secundárias, pastagens, hortas, áreas de pousio, áreas de plantio, corpos d'água e áreas construídas. Representam, dessa maneira, um sistema integrado de produção; o que contribui para obter rendimento nas colheitas e para proteger o ecossistema, já que mantêm "corredores naturais" para vetores de animais e propágulos entre as áreas de naturais e de cultivo. A diversidade de produtos cultivados também favorece um uso mais eficiente do esforço do produtor ao longo do ciclo anual, pois concilia a atividade produtora e os ciclos naturais durante todo o ano. Assim, esses sistemas mantêm e promovem duas características ambientais: heterogeneidade espacial e diversidade biológica (Posey, 1986; Toledo \& BarreraBassols, 2015).

Em relação à prática tradicional local, o pousio representa um nítido conhecimento e adaptação dos produtores aos processos sucessionais da floresta. Cabe destacar o estudo sobre a prática de pousio adotado na região da APAMC, em comparação com áreas de plantio convencional e com uma área florestal em estágio sucessional avançado (Bertolino \& Bertolino, 2010). Esse estudo demonstrou que a vegetação das áreas em pousio estudadas estava em um estágio inicial de regeneração e que as propriedades físicas e químicas do solo das áreas em pousio apresentaram características próximas à da área florestal (Bertolino \& Bertolino, 2010).

Vale evidenciar a existência de algumas alternativas de renda que demandam algum grau de conservação do sistema e cuidado com o ambiente, como, por exemplo, a produção de mel, aplicada nas Áreas de Preservação Permanente (Sousa et al., 2019). E, também, o emprego de técnicas de conservação dos solos e recursos naturais, como o plantio em curvas de nível; a construção de terraços; a manutenção da umidade do solo com cobertura morta (restos e palhada) e o cercamento de nascentes e dos corpos hídricos (Sousa et al., 2019).

Os(as) agricultores(as) adotam manejos específicos dos recursos naturais, adequados às dificuldades encontradas; são protagonistas na gestão desses recursos nas áreas rurais. Porém, apesar da importância dos agricultores por fornecerem uma produção diversificada para a população, recai sobre eles o ônus da conservação ambiental; enquanto seus benefícios são aproveitados por outros setores da sociedade (Hogan, 2007; Toledo \& Barrera-Bassols, 2015). Os relatos dos agricultores dão conta de que os mesmos insistem na atividade pela paixão e pelo reconhecimento da importância da agricultura, mas se sentem marginalizados e desvalorizados (Carneiro, 2010; Sousa et al., 2019). Essas dificuldades impostas aos 
agricultores familiares têm servido de desestímulo à produção agrícola, o que leva a movimentos migratórios de saída do campo ou mesmo ao arrendamento para pecuária, com decorrente investimento em outras atividades. Movimentos que têm transformado o perfil da Serra Fluminense.

O movimento de agricultores observado na serra macaense tem sido registrado em vários outros municípios e apontado como causa para recentes efeitos definidos como Transição Florestal (Silva, Becker \& Martins, 2015). Para o território macaense já foi registrado, em um período de cinco anos, o aumento de cobertura florestal da ordem de 6,2\%; de forma que a cobertura florestal do município variou de $434 \mathrm{Km}^{2}$, em 2013, para $461 \mathrm{Km}^{2}$ em 2017; as áreas destinadas à agropecuária reduziram 4\%; e a área urbana expandiu 11\% (Martins, Molisani \& Rocha, 2019, com base em dados do Projeto MapBiomas, 2018).

Quanto aos documentos de gestão ambiental citados, é possível perceber a presença de diversos programas voltados especialmente para as populações locais, focados nos agricultores familiares, do alto curso, e nos pescadores, presentes na parte baixa da Bacia. Destaca-se o envolvimento dos agricultores na formulação dessas políticas e a forma que as mesmas resultaram da luta, resistência e organização dos agricultores. Esse envolvimento promoveu o reconhecimento da necessidade do resgate e da valorização de aspectos da cultura local, além da conservação ambiental, pela manutenção das condições e práticas que garantiram a sobrevivência da floresta até o atual momento (Azevedo, 2017; Sousa et al., 2019).

A importância da agricultura de base familiar é reafirmada no relatório do Programa das Nações Unidas para o Meio Ambiente (PNUMA) e do Fundo Internacional de Desenvolvimento Agrícola (IFAD) "Smallholders, Food Security, and the Environment" (2013). O relatório apresenta que os agricultores são atores importantes que, a partir de seus conhecimentos locais, podem oferecer caminhos práticos para uma agricultura mais sustentável, de forma a alcançar a subsistência e um pequeno comércio de excedentes, com qualidade e, portanto, garantir a segurança alimentar e nutricional. Enfim, uma estratégia para o desenvolvimento da sociedade, das culturas e tradições regionais e para a conservação da natureza e dos modos de vida.

Com relação aos documentos de planejamento e gestão do território, todos parecem atentos às questões relacionadas à sustentabilidade dos modelos de produção agrícola que possam garantir o sustento e a manutenção da segurança hídrica e alimentar da região. Isso ocorre muito graças à participação de associações de agricultores na formulação de tais documentos. A falta de incentivos e recursos públicos e privados talvez tenha sido uns dos principais entraves para a ampliação e a implementação de ações sustentáveis, que beneficiem toda RH VIII (Azevedo, 2017). Uma possibilidade de conseguir recursos para implementar os programas do PRH da RH VIII e/ou os Planos de Manejo em questão é através de projetos de compensação ambiental dos empreendimentos existentes e futuros (Azevedo, 2017).

Todos os documentos reconhecem a necessidade de uma conciliação entre a produção agrícola, o turismo e a conservação ambiental. Entretanto, o turismo parece ser o único a figurar como um novo elemento, mais alinhado a um modelo de desenvolvimento e conservação de uma elite. Essa elite nem sempre está alinhada com questões de sobrevivência de modos de vida mais dependentes da natureza e do uso sustentável da mesma (Diegues, 1998). Nesse quadro, os novos moradores, sitiantes e turistas do Alto Rio Macaé, trazem novos discursos e práticas, que afetaram diretamente o modo de vida da população local: denunciam os agricultores; mudam a dinâmica de produção de lixo e esgoto; constroem em áreas protegidas ou cobram o acesso aos pontos de banho de rio (Carneiro, 2010; CBH Macaé, 2016; Rego, 2010).

Sobre esse turismo "novo", o ordenamento previsto pelo documento do Comitê de Bacia, que visa a enfrentar os problemas decorrentes do uso desordenado das cachoeiras, poços e rios (Ferreira \& Rego, 2017; INEA et al., 2014), reflete bem a tensão que se instala com relação ao uso turístico da área. O que temos na região é um quadro conflitivo: os agricultores se veem como responsáveis pelo atual estado de conservação, produzido por práticas culturais locais, que representa o atrativo para o turismo de base ecológica. No entanto, esse estado de conservação, que se reflete em lucros para uma nova elite local, força a adoção de medidas de conservação mais restritivas e ações de fiscalização; além de promover um controle do acesso a antigos pontos de lazer. Na prática, em nome da conservação, esses espaços se transformam em empreendimentos comerciais, voltados para o lucro do proprietário, sem o cuidado 
ambiental justificado e prometido. Uma transformação que compromete o acesso a um patrimônio coletivo (CBH Macaé, 2016; Ferreira \& Rego, 2017). Enfim, o conflito se estabelece, portanto, entre os moradores, os turistas e os empresários do turismo e os proprietários dessas áreas. Conflitos existentes tanto na APAMC, quanto na APA do Sana (Ferreira \& Rego, 2017).

O conflito traz consigo a possibilidade de transformação e mudança. Mas, para isso, a participação de todos os envolvidos (ou de seus representantes) e a cultura do diálogo, em que todas as partes tenham voz, são ferramentas fundamentais para se alcançar os objetivos desejados (Theodoro, Cordeiro \& Beke, 2004). O Estado, através da gestão ambiental, é o responsável por gerenciar e favorecer a mediação dos conflitos entre os atores sociais pelo acesso e uso dos recursos ambientais, sendo essa gestão de interesse público (Pinto, Machado \& Vilani, 2015). No entanto, nem sempre os órgãos governamentais atuam de maneira eficiente para gerenciar esses conflitos. Assim, muitas vezes, entidades locais assumem o papel de mediação (Theodoro et al., 2004).

Portanto, cabe destacar a existência de iniciativas locais, atentas aos problemas decorrentes do turismo e sua potencialidade como gerador de renda. São iniciativas que buscam, por meio do fortalecimento da continuidade dos modelos de produção local e de suas práticas, garantir as condições ambientais, que levaram a área a ser reconhecida como propícia ao turismo ecológico e conservação. Pode ser citada, por exemplo, a rede "Altos da Serramar, Circuitos de Agroturismo" (Altos da Serramar, 2020), que agrega 41 propriedades rurais, localizadas nos distritos de Mury, Lumiar e São Pedro da Serra, em Nova Friburgo; Barra Alegre, no município de Bom Jardim e Monte Cristo, em Trajano de Moraes. A iniciativa surgiu a partir de uma pesquisa acadêmica, que teve por objetivo identificar e quantificar a produção agrícola e o consumo destes no distrito de São Pedro da Serra e suas adjacências, de modo a colaborar para a formação e dinamização de circuitos curtos de comercialização dos alimentos produzidos pelos agricultores familiares da região (Carneiro \& Palm, 2015). O agroturismo, nesse contexto, constitui uma forma de geração de renda complementar para as famílias de agricultores e produtores da região e promove um espaço de debate entre esses atores sobre qual turismo é possível construir (Caldas \& Azevedo, 2018).

A existência de situações conflitivas tem promovido na região a criação de diversas frentes de enfrentamento e resistência na forma de associações e grupos (ver também Sousa et al. 2019). Essas associações têm se organizado na participação de fóruns e instâncias de representação junto ao Município (Conselhos de Agricultura e de Meio Ambiente) e ao Estado (Comitê de Bacia, Conselhos Gestores de UCs). Ou seja, atuam na formulação de instrumentos de gestão, que tratam de um elemento em comum: o ambiente, que engloba tanto a dimensão física e biológica, quanto a dimensão social; dimensões que são interdependentes entre si (Little, 2004).

Por fim, é importante destacar os desafios do atual momento de reestruturação econômica do município de Macaé, diante de um quadro de crise do setor de exploração de petróleo e do aporte de uma série de novos investimentos, que visam a ampliar a produção energética a partir do gás (Nader, 2019). Esse momento tem aumentado as discussões sobre a capacidade e a disponibilidade hídrica do Rio Macaé, já que amplia ainda mais a pressão sobre a conservação das águas (Ferreira, Quintanilha, Guimarães, \& Molisani, 2019) e, consequentemente, sobre o papel dos agricultores da serra. A nova agenda político-econômica demandará ainda maior envolvimento dos agricultores na gestão dos recursos hídricos de forma articulada e integrada à gestão da biodiversidade e à população local (Azevedo, 2017). O que exige, acima de tudo, a capacitação da população para a gestão participativa e o desenvolvimento de ações de caráter dialógica, crítico e transformador (Carvalho, 2004).

Dessa forma, o processo de reestruturação econômica do município de Macaé deve ser tratado como um momento crítico e oportuno para que o município diversifique a sua matriz econômica (Silva \& Carvalho, 2019). E pode ser aproveitado pelos agricultores para se discutir um novo modelo de desenvolvimento mais sustentável, principalmente por aqueles organizados pela experiência de gestão do território. Uma sustentabilidade que seja integral, que incorpore não só os ganhos econômicos dos investidores e a perenidade dos novos empreendimentos, como também as potencialidades e os projetos locais. Ou seja, construir uma agricultura e um turismo sustentáveis de base comunitária, de maneira que sejam garantidos investimentos em ações de tratamento de esgotos e de educação ambiental para moradores e visitantes da Região Serrana. 


\section{Conclusão}

Nesse artigo evidenciamos a importância da Serra Macaense para o município de Macaé, cujo executivo e setor privado alinham um novo projeto de crescimento do município. Discute-se a importância de se garantir a sustentabilidade desse projeto com investimentos que vão para além da área urbanizada nas regiões costeiras, ou seja, considerando a bacia hidrográfica do Rio Macaé como unidade de planejamento territorial. A sustentabilidade demanda investimento em modelos já implementados de agricultura na região, que almejam alinhar a produção de alimentos saudáveis e o desenvolvimento de turismo ambiental sustentável, com foco na proteção dos recursos hídricos, o que pode representar excelente estratégia para a conservação ambiental, com o envolvimento da população.

Constatou-se que os agricultores familiares da APAMC pertencentes ao Alto Rio Macaé desenvolvem importantes práticas com características típicas de unidades de produção tradicional, com reconhecida influência na conservação das águas, dos solos, da biodiversidade e da cultura local. Das práticas tradicionais locais, o uso do pousio ou descanso da terra, atrelado à rotação de culturas, representam o conhecimento e adaptação dos(as) agricultores(as) aos ambientes florestais. Prática que está sendo perdida pelo processo de modernização da agricultura e pela aplicação da legislação ambiental de maneira agressiva. Ficou evidente o protagonismo dos agricultores(as) na gestão dos recursos naturais, com seus manejos específicos da natureza, adequados às dificuldades encontradas. Protagonismo fundamental na construção da sustentabilidade nas áreas rurais.

Observou-se também um movimento de redução do interesse pela atividade agrícola, principalmente, pelos mais jovens, o que foi relacionado à possibilidade de obter outras fontes de renda, muitas vezes mais valorizadas que a agricultura. Os(as) entrevistados(as) relataram que se mantêm na agricultura por ter paixão e buscam a valorização da agricultura familiar. Um caminho encontrado pelos(as) agricultores(as) de continuar com a agricultura é o sistema de pluriatividade, no qual são exercidas outras atividades econômicas, somadas à agricultura. Como o turismo é uma atividade de grande relevância na região, muitas dessas outras atividades são relacionadas ao turismo. Uma das maneiras que os agricultores encontraram de se integrar a essa nova realidade, com a união da agricultura com o turismo, foi com a construção de uma rede de agroturismo. Espaço de geração de renda complementar e de discussão sobre a construção de um turismo de base comunitária.

Uma das questões também apontadas como causa da diminuição da atividade agrícola na região foi a estrita aplicação da legislação ambiental, principalmente, no início dos anos 2000, com a criação da APA Estadual Macaé de Cima. Fato que desencadeou conflitos entre os agricultores locais, novos moradores e sitiantes e os órgãos ambientais. Esse conflito foi responsável pelo desenvolvimento de importantes associações, como o Conselho Consultivo da própria APAMC, responsável pela interlocução entre os gestores da APA e os agricultores. Nos últimos anos, os conflitos existentes mais significativos são: a especulação imobiliária; a poluição das águas por esgoto; o crescimento populacional desordenado e o cercamento dos acessos aos pontos de banho de rio. Diante desse quadro, iniciativas que integrem essas características e potencialidades regionais, com o objetivo de tornar a região cada vez mais sustentável, são urgentes e necessárias.

Planos de desenvolvimento local parecem atentos às questões relacionadas à sustentabilidade dos modelos de produção agrícola e foram construídos com a participação e envolvimento dos agricultores. Esse envolvimento promoveu o reconhecimento da necessidade da valorização de aspectos da cultura local, além da conservação ambiental, pela manutenção das condições e práticas que garantiram a sobrevivência da floresta até o atual momento. No entanto, um dos principais desafios é a implementação desses programas, principalmente por falta de recursos financeiros, além das dificuldades políticas e burocráticas.

Apesar de ainda existirem muitos desafios e conflitos, as iniciativas apresentadas consideram a importância do fortalecimento de ações que garantam a sobrevivência de outros modos de produção, de forma que inclua os diferentes projetos de território, especialmente com a inclusão das populações de agricultores familiares (re)existentes na Região Serrana de Macaé. Para tanto, será cada vez mais necessário um maior envolvimento dos agricultores na gestão ambiental do território nessa nova agenda político-econômica, o que exige, acima de tudo, a capacitação da população para a gestão participativa. 
Realizar ações para conservação, recuperação e manejo da natureza, aliadas à participação social, são um grande desafio para a sociedade. Fazer uma gestão que seja de fato participativa e integrada é uma tarefa difícil, seja pelas novas relações de poder que se constroem, dando voz às minorias; pela educação política da sociedade, que não está acostumada a participar desses espaços e/ou pela falta de uma educação ambiental para sensibilizar a população da necessidade de conservar a natureza e adotar práticas sustentáveis em todos os aspectos da sociedade. Isso porque se trata da construção de novas relações sociais e da consideração de uma relação mais integrada entre o ser humano e o seu ambiente, processo que ainda está incipiente.

\section{Agradecimentos}

Agradecemos a CAPES - Coordenação de Aperfeiçoamento de Pessoal de Nível Superior, pela concessão da Bolsa de Mestrado CAPES-Demanda Social (DS). Agradecemos também ao $\mathrm{CNPq}$ - Conselho Nacional de Desenvolvimento Científico e Tecnológico, por meio da Chamada MCTI/CNPq no 20/2017 - Nexus II: Pesquisa e Desenvolvimento em Ações Integradas e Sustentáveis para a Garantia da Segurança Hídrica, Energética e Alimentar nos Biomas Pampa, Pantanal e Mata Atlântica. Instituições e financiamentos fundamentais para o desenvolvimento desta pesquisa. 


\section{Referências}

Altieri, M. A. (2012). Agroecologia: bases científicas para uma agricultura sustentável. (3a ed.) São Paulo, SP/ Rio de Janeiro, RJ: Expressão Popular e AS-PTA.

ALTOS DA SERRAMAR. (2020, 15 março). Propriedades. Recuperado de https://altosdaserramar.com.br/propriedades/

Azevedo, A. S. R. (2017). Unidades de Conservação e Recursos Hídricos: Uma Possibilidade de Gestão Integrada - O Caso da Área de Proteção Ambiental Estadual Macaé de Cima, Nova Friburgo, Rio de Janeiro (Monografia de Especialização). Escola Nacional de Ciências Estatísticas, Rio de Janeiro, RJ, Brasil.

Bertolino, A. V. F. A., \& Bertolino, L. C. (2010). Agricultura migratória e seus efeitos sobre o solo. In M. J. CARNEIRO, A. V. F. A. Bertolino, \& L. C. Bertolino (Eds.), Agricultores e territórios: práticas e saberes (pp.51-72). Rio de Janeiro, RJ: Trasso Comunicação.

Bursztyn, M. A., \& Bursztyn, M. (2012). Fundamentos de Política e Gestão Ambiental: caminhos para a sustentabilidade. Rio de Janeiro, RJ: Garamond.

Caldas, L. C. C., \& Azevedo, A. S. R. (2018). Altos da Serramar, Circuitos de Agroturismo. Nova Friburgo, RJ: Casa dos Saberes.

Carneiro, M. J. (2010). O agricultor na natureza e na sociedade. In M. J. Carneiro, A. V. F. A. Bertolino, \& L. C. Bertolino (Eds.), Agricultores e territórios: práticas e saberes (pp.9-50). Rio de Janeiro, RJ: Trasso Comunicação.

Carneiro, M. J., \& Palm, J. L. (2015). Agricultura Familiar: produção, venda e consumo. Nova Friburgo, RJ: Instituto de Imagem e Cidadania.

Carvalho, I. C. M. (2004). Educação Ambiental Crítica: nomes e endereçamentos da educação. In P. P. LAYRARGUES (Coord.), Identidades da educação ambiental brasileira. Brasília, DF: Ministério do Meio Ambiente.

COMITÊ DE BACIA HIDROGRÁFICA DO RIO MACAÉ E DAS OSTRAS [CBH Macaé]. (2016). Diagnóstico socioambiental e projeto técnico de ações de conservação do solo e da água da sub bacia do alto curso do Rio Macaé. Lumiar, RJ: CBH Macaé.

COMITÊ DE BACIA HIDROGRÁFICA DO RIO MACAÉ E DAS OSTRAS [CBH Macaé]. (2019, abril). Boletim informativo: [Informativo CILSJ/CBH Macaé 02/2019]. Recuperado de http://cbhmacae.eco.br/site/wpcontent/uploads/2019/04/Informativo-CILSJ_CBH-Macae_-N\%C2\%BA-02_19.pdf

Demo, P. (2002). Pesquisa Social. In P. DEMO. Introdução à sociologia: complexidade, interdisciplinaridade e desigualdade social. São Paulo, SP: Editora Atlas.

Diegues, A. C. S. (1998). O Mito Moderno da Natureza Intocada .2. ed.) São Paulo, SP: Editora HUCITEC.

EMPRESA BRASILEIRA DE PESQUISA AGROPECUÁRIA [EMBRAPA]. (2006). Marco Referencial em Agroecologia. Brasília, DF: EMBRAPA Informação Tecnológica.

Esteves, F. A., Martins, R. L., Molisani, M. M., Petry, A. C., Costa, R. N., Menezes, J. S., Fonseca, R. N. (2015). Carta das águas de Macaé: Contribuição do NUPEM/UFRJ para a governança dos recursos hídricos de Macaé. Revista do Núcleo em Ecologia e Desenvolvimento Socioambiental de Macaé, (6).

Ferreira, M. I., Quintanilha, G. J., Guimarães, E. A., \& Molisani, M. M. (2019). Gestão integrada das águas e desenvolvimento local. In S. C. R. Silva \& M. R. Carvalho (Orgs.), Macaé do caos ao conhecimento: olhares acadêmicos sobre o cenário de crise econômica (pp. 523-544). Macaé, RJ: Prefeitura Municipal de Macaé.

Ferreira, M. I. P., \& Rego, V. V. B. S. (2016). Gestão participativa de Bacias Hidrográficas relacionadas com áreas protegidas no Brasil: o caso da Região Hidrográfica VIII do Estado do Rio de Janeiro e da Área de Proteção Ambiental do Macaé de Cima. In R. Stachiw, \& N. Caramello (Orgs.), Amazônia: instrumentos para gestão de recursos hídricos (pp.393-412). Curitiba, PR: Editora CRV.

Ferreira, M. I. P. \& Rego, V. V. B. S. (2017, outubro). Oficina de fortalecimento do conselho gestor da APA do Sana: capacitação em gestão participativa relatório técnico - Comitê de Bacia Hidrográfica dos Rios Macaé e das Ostras. In Anais do VIII Seminário Brasileiro sobre Áreas Protegidas e Inclusão Social e III Encontro Latino-Americano sobre Áreas Protegidas e Inclusão Social. Niterói, RJ, Brasil.

Gil, A. C. (1987). Métodos e técnicas de pesquisa social 2. ed. São Paulo, SP: Editora Atlas.

Hogan, D. J. (Org.). (2007). Dinâmica populacional e mudança ambiental: cenários para o desenvolvimento brasileiro. Campinas, SP: Núcleo de Estudos de População-Nepo/Unicamp.

INSTITUTO ESTADUAL DO AMBIENTE [INEA]. (2014). APA Estadual de Macaé de Cima: Plano de Manejo. Rio de Janeiro, RJ: INEA.

INSTITUTO ESTADUAL DO AMBIENTE [INEA], Comitê de Bacia do Rio Macaé e das Ostras [CBH Macaé] \& Consórcio Macaé/Ostras. (2014). Plano de Recursos Hídricos da Região Hidrográfica Macaé/Ostras. Rio de Janeiro, RJ: INEA.

Jeronymo, C. A. L. (2012). Identificação de Áreas Prioritárias, com uso de Geoprocessamento, para Conservação e Recuperação da Área De Preservação Ambiental Do Sana, Macaé-RJ (Dissertação de Mestrado). Instituto Federal Fluminense, Macaé, RJ, Brasil.

LEI N 9.985, DE 18 DE JULHO DE 2000. (2000). Regulamenta o art. 225, § 1o, incisos I, II, III e VII da Constituição Federal, institui o Sistema Nacional de Unidades de Conservação da Natureza e dá outras providências. Brasília, DF. Recuperado de http://www.planalto.gov.br/ccivil_03/leis/L9985.htm

Little, Paul E. (2004, maio). A etnografia dos conflitos socioambientais: bases metodológicas e empíricas. In Anais do II Encontro da Associação Nacional de Pós-graduação e Pesquisa em Ambiente e Sociedade (ANPPAS). Indaiatuba, SP, 
Brasil.

Martins, R. L., Molisani, M. M., \& Rocha, G. B. (2019). Impactos e perspectivas ambientais diante da crise do petróleo e da reestruturação social e econômica do município de Macaé. In S. C. R. Silva \& M. R. Carvalho (Orgs.), Macaé do caos ao conhecimento: olhares acadêmicos sobre o cenário de crise econômica. (pp. 312-326). Macaé, RJ: Prefeitura Municipal de Macaé.

Nader, G. L. (2019). Uma nova centralidade para Macaé. Revista online Espaço e Economia, Ano VII, (14). Doi: http://journals.openedition.org/espacoeconomia/6197

Pina, J. H. A., \& Ferreira, V. O. (2010, julho). A Importância da Relação Entre o Sistema Nacional de Unidades de Conservação e a Política Nacional de Recursos Hídricos: Possibilidades para uma Gestão Integrada. In Anais do XVI Encontro Nacional dos Geógrafos. Porto Alegre, RS, Brasil.

Pinto, N. M., Machado, C. J. M., \& Vilani, R. M. (2015). Educação Ambiental: uma proposta para o fortalecimento da participação popular no licenciamento de atividades petrolíferas no Brasil. Revista Políticas Públicas, 19(1), 117-131. Doi: http://dx.doi.org/10.18764/2178-2865.v19n1p117-131

Posey, D. A. (1987). Introducão - Etnobiologia: Teoria e Prática. In RIBEIRO, B. (Coord./Org.). Suma etnológica brasileira (Vol. 1). Petrópolis, RJ: Vozes/FINEP.

Poupart, J. (2012). A entrevista de tipo qualitativo: considerações epistemológicas, teóricas e metodológicas. In J. Poupart, J. Deslauriers, L. H. Groulx, A. Laperrière, R. Mayer, \& A. Pires (Orgs). A pesquisa qualitativa: enfoques epistemológicos e metodológicos (3a ed., pp. 215-253) Petrópolis, RJ: Vozes.

PROGRAMA DAS NAÇÕES UNIDAS PARA O MEIO AMBIENTE [PNUMA] \& Fundo Internacional de Desenvolvimento Agrícola [IFAD]. (2013). Smallholders, Food Security, and the Environment. Recuperado de https://www.ifad.org/documents/38714170/39135645/smallholders_report.pdf/133e8903-0204-4e7d-a780-bca847933f2e

PROJETO MAPBIOMAS. (2018). Série anual de mapas de cobertura e uso de solo do Brasil (Coleção 3). Recuperado de http://mapbiomas.org/map\#coverage

Rego, V. V. B. S. (2010). Paraísos perdidos ou preservados? Os múltiplos sentidos da cidadania em Áreas de Proteção Ambiental (Tese de Doutorado). Universidade do Estado do Rio de Janeiro, Rio de Janeiro, RJ, Brasil.

Santilli, J. F. R. (2009). Agrobiodiversidade e direito dos agricultores (Tese de Doutorado). Pontifícia Universidade Católica (PUC-PR), Curitiba, PR, Brasil.

Silva, J. A. A., Becker, B. R., \& Martins, R. L. (2015). Macaé e a sustentabilidade do projeto de "capital nacional do petróleo". Revista online Espaço e Economia, Ano IV, (7), 1-21. Doi: 10.4000/espacoeconomia.1875

Silva, C. R., Gobbi, B. C., \& Simão, A. A. (2005). O uso da análise de conteúdo como uma ferramenta para pesquisa qualitativa: descrição e aplicação do método. Organizações Rurais \& Agroindustriais, 7(1), 70-81. Recuperado de http://revista.dae.ufla.br/index.php/ora/article/view/210/207

Silva S. C. R., \& Carvalho M. R. (Org.). (2019). Macaé do caos ao conhecimento: olhares acadêmicos sobre o cenário de crise econômica. Macaé, RJ: Prefeitura Municipal de Macaé.

Sousa, R. T. S., Azevedo, A. S. R., \& martins, R. L. (2019, outubro). Agricultura Familiar e Áreas de Preservação Permanente na Percepção de Agricultores em um trecho da Bacia Hidrográfica do Rio Macaé. In Anais do IX Encontro Nacional da Associação de Pós-Graduação e Pesquisa em Ambiente e Sociedade. Brasília, DF, Brasil.

Theodoro, S. H., Cordeiro, P. M. F., \& Beke, Z. (2004, maio). Gestão Ambiental: Uma prática para mediar conflitos socioambientais. In Anais do II Encontro da Associação Nacional de Pós-Graduação e Pesquisa em Ambiente e Sociedade. São Paulo, SP, Brasil.

Toledo, V. M., \& Barrera-Bassols, N. (2015). A Memória Biocultural: A importância ecológica das sabedorias tradicionais. São Paulo, SP: Expressão Popular.

Villas Boas, G. H. (2017). Etnogeomorfologia da APA Macaé de Cima: um objetivo e dois saberes (Tese de Doutorado). Universidade Federal do Rio de Janeiro, Rio de Janeiro, RJ, Brasil.

VIVA RIO. (2004). Plano de Manejo da APA do Sana. Rio de Janeiro, RJ: Viva Rio/Prefeitura Municipal de Macaé.

Wymann Von Dach s., Romeo R., Vita A., WURZINGER M., \& KOHLER T. (Eds). (2013). La Agricultura de montaña es agricultura familiar: Una contribución de las zonas de montaña al Año Internacional de la Agricultura Familiar 2014. Roma, Italia: FAO, CDE, BOKU. 